\title{
Spontaneous formation of IpaB ion channels in host cell membranes reveals how Shigella induces pyroptosis in macrophages
}

\author{
L Senerovic ${ }^{1,2}$, SP Tsunoda ${ }^{3}$, C Goosmann ${ }^{4}$, V Brinkmann ${ }^{4}$, A Zychlinsky ${ }^{1}$, F Meissner $^{1,5}$ and M Kolbe ${ }^{\star, 1}$
}

The Gram-negative bacterium Shigella flexneri invades the colonic epithelium and causes bacillary dysentery. $S$. flexneri requires the virulence factor invasion plasmid antigen $B(\mathrm{IpaB})$ to invade host cells, escape from the phagosome and induce macrophage cell death. The mechanism by which IpaB functions remains unclear. Here, we show that purified IpaB spontaneously oligomerizes and inserts into the plasma membrane of target cells forming cation selective ion channels. After internalization, IpaB channels permit potassium influx within endolysosomal compartments inducing vacuolar destabilization. Endolysosomal leakage is followed by an ICE protease-activating factor-dependent activation of Caspase-1 in macrophages and cell death. Our results provide a mechanism for how the effector protein IpaB with its ion channel activity causes phagosomal destabilization and induces macrophage death. These data may explain how S. flexneri uses secreted IpaB to escape phagosome and kill the host cells during infection and, may be extended to homologs from other medically important enteropathogenic bacteria.

Cell Death and Disease (2012) 3, e384; doi:10.1038/cddis.2012.124; published online 6 September 2012

Subject Category: Immunity

Shigella flexneri is a Gram-negative enteroinvasive bacterium and the main cause of bacillary dysentery with estimated one million deaths per year, predominantly children under the age of 5 years. ${ }^{1} S$. flexneri invades the colonic epithelium and induces a severe inflammatory response at the site of infection. ${ }^{2}$ Once ingested, S. flexneri reaches the colon and rectum where it crosses the epithelial barrier via M cells. In the adjacent mucosal lymphoid tissue, bacteria are phagocytosed by resident macrophages, quickly escape the phagosome and cause macrophage cell death. ${ }^{3}$ Caspase- 1 activation and the death of $S$. flexneri-infected macrophages release mature interleukin $1 \beta$ (IL-1 $\beta$ ) and IL-18 and trigger the inflammatory response and symptoms typical of shigellosis. ${ }^{4}$ This pathology requires the transport of $S$. flexneri virulence proteins (effectors) into mammalian cells through a specialized secretion machinery called the type III secretion system (TTSS). ${ }^{5}$

Invasion plasmid antigen $\mathrm{B}$ (IpaB) is a $62 \mathrm{kDa}$ protein and one of the first effectors secreted by $S$. flexneri. It is stored in the bacterial cytoplasm bound to its chaperone invasion plasmid gene $\mathrm{C}(\mathrm{IpgC})$, which is released before IpaB secretion. ${ }^{6,7}$ IpaB is essential for $S$. flexneri virulence as bacteria lacking ipa $B$ fail to invade epithelial cells and to activate Caspase-1 in macrophages. ${ }^{8,9}$ The current model of $S$. flexneri infection postulates that secreted IpaB, together with IpaC, forms a translocon that transports bacterial effectors across the host cell membrane. ${ }^{10}$ It was also assumed that $S$. flexneri requires IpaB to lyse the phagosomal membrane based on the results showing that IpaB alone can destabilize model membranes, ${ }^{11}$ and that strains where ipa $B$ was deleted do not have contact hemolytic activity. ${ }^{10,12}$ The previous data suggest a dual function for IpaB, one in concert with IpaC facilitating the transport of other Shigella virulence factors in host cells and the second inducing pyroptosis in infected cells without binding to IpaC.

During invasion of host cells by different pathogens, microbial factors such as flagellin or pore forming toxins (PFTs) activate inflammasomes of distinct compositions. ${ }^{13}$ Inflammasomes are cytosolic complexes that mediate maturation of the $45 \mathrm{kDa}$ pro-Caspase- 1 into its enzymatically

\footnotetext{
${ }^{1}$ Department of Cellular Microbiology, Max-Planck-Institute for Infection Biology, Charitéplatz 1, D-10117 Berlin, Germany; ${ }^{2}$ Laboratory for Microbial Molecular Genetics and Ecology, Institute of Molecular Genetics and Genetic Engineering, University of Belgrade, Vojvode Stepe 444a, PO Box 23, 11010 Belgrade, Serbia; ${ }^{3}$ Experimental Biophysics, Institute of Biology, Invalidenstrasse 42, D-10115 Berlin, Germany; ${ }^{4}$ Core Facility Microscopy, Max-Planck-Institute for Infection Biology, Charitéplatz 1 , D-10117 Berlin, Germany and ${ }^{5}$ Proteomics and Signal Transduction, Max-Planck-Institute for Biochemistry, Am Kloperspitz 18, D-82152 Martinsried, Germany ${ }^{*}$ Corresponding author: M Kolbe, Department of Cellular Microbiology, Max-Planck-Institute for Infection Biology, Charitéplatz 1, D-10117 Berlin, Germany. Tel: +49 3028460 332; Fax: +49 3028460 301; E-mail: kolbe@mpiib-berlin.mpg.de.

Keywords: IpaB; Shigella flexneri; ion channel; endocytosis; macrophages; pyroptosis

Abbreviations: $\mathrm{AO}$, acridine orange; ASC, apoptosis-associated speck-like protein containing caspase recruitment domain; BMM, bone marrow-derived macrophages; CMC, critical micelle concentration; DTSSP, 3,3-dithiobis (sulfosuccinimidylpropionate); EPXMA, electron probe X-ray microanalysis; hMF, human monocyte-derived macrophages; IpaB $(C)$, invasion plasmid antigen $\mathrm{B}(\mathrm{C})$; IPAF, ICE protease-activating factor; LDAO, N,N-dimethyldodecylamine-N-oxide; $L D H$, lactate dehydrogenase; LPS, lipopolysaccharides; LUV, large unilamellar vesicle; NALP3, NACHT, LRR and PYD domains-containing protein 3; NMG +, N-methylglucamine; PBMC, peripheral blood mononuclear cells; PFT, pore forming toxin; RBC, red blood cells; SEC, size exclusion chromatography; TEA, tetraethyl ammonium; TEM, transmission electron microscopy; TEVC, two-electrode voltage clamp; TLR, toll-like receptor; TTSS, type III secretion system; TUNEL, terminal deoxynucleotidyl transferase dUTP nick end labeling

Received 18.1.12; revised 13.6.12; accepted 02.7.12; Edited by H-U Simon
} 
active form composed of subunits p10 (10 kDa) and p20 $(20 \mathrm{kDa}){ }^{14}$ The active inflammasome is critical to process and release IL-1 $\beta$ and IL-18. ${ }^{15}$ Inflammasome containing ICE protease-activating factor (IPAF) and apoptosis-associated speck-like protein containing a caspase recruitment domain (ASC) is formed in response to intracellular pathogens like Salmonella typhimurium, Legionella pneumophila, Pseudomonas aeruginosa and S. flexneri. ${ }^{16-19}$ IPAF was identified as a cytosolic sensor of bacterial flagellin. ${ }^{20}$ Interestingly, S. flexneri lacks flagellin, making it unclear, which stimulus triggers the IPAF and inflammasome formation during infection. Although indirect evidence suggests that bacterial $i p a B$ expression is required for the activation of the IPAF inflammasome, ${ }^{9,21}$ the underlying mechanism of $S$. flexneriinduced cytotoxicity remains unclear.

In order to understand the functional mechanism of how IpaB induces the cell death of macrophages, we developed a procedure to purify active IpaB and studied its function in the absence of other $S$. flexneri effectors. We show that IpaB inserts into the host plasma membrane after spontaneous oligomerization and forms channels selective for monovalent anorganic cations. Internalized IpaB ion channels disturb the ion homeostasis within endolysosomal compartments. The subsequent membrane disintegration and endolysosomal leakage are followed by Caspase- 1 activation through an IPAF/ASC inflammasome and macrophage cell death. Our results may explain how pathogenic bacteria expressing TTSS employ secreted translocators to escape from phagosomes and induce cell death in infected cells.

\section{Results}

IpaB oligomers permeabilize membranes. S. flexneri secretes IpaB without contacting host cells. ${ }^{22}$ To understand the role of secreted IpaB, we studied the function of the purified protein. We coexpressed ipaB, together with its cognate chaperone, ipgC, heterologously in E. coli. ${ }^{23} \mathrm{We}$ later separated IpaB from affinity bound histidine-tagged IpgC using the detergent $\mathrm{N}, \mathrm{N}$-dimethyldodecylamine- $\mathrm{N}$-oxide (LDAO) and purified it further by size exclusion chromatography (SEC) in the presence of LDAO (Supplementary Figure 1a).

Limited proteolysis with thermolysin yielded a stable IpaB fragment of $40 \mathrm{kDa}$ both on ice and at room temperature (Supplementary Figure 1b). Matrix-assisted laser desorptionionization mass spectrometry analysis identified the region between amino acid 116 and 482 as the IpaB stable core (Supplementary Figure 1c). These data indicate that IpaB is folded and stable after purification in the presence of LDAO.

IpaB secreted from $S$. flexneri inserts into membranes ${ }^{10}$ and can disrupt them. ${ }^{11,12}$ To test whether IpaB that we purified induces membrane disintegration, we incubated the effector with large unilamellar vesicles (LUVs) composed of typical eukaryotic plasma membrane lipids such as phosphatidylcholine (PC), phosphatidylserine (PS), phosphatidylethanolamine (PE), sphingomyelin (SM) and phosphatidylinositol (PI). The LUVs were loaded with calcein, a dye that quenches itself at high concentrations. Fluorescence increases when the dye is released from the vesicles, indicating membrane damage. IpaB, but not LDAO-containing buffer, disrupted the LUVs within seconds in a dosedependent manner (Figure 1a). Next, we examined the interaction of IpaB with eukaryotic plasma membranes and incubated sheep red blood cells (RBCs) with purified protein. We monitored the release of hemoglobin and showed that IpaB-induced hemolysis is dose-dependent (Figure 1b). Together, these data show that IpaB permeabilizes eukaryotic membranes and correlate with previous reports showing that S. flexneri contact hemolysis requires IpaB. ${ }^{10,12,24}$

To study IpaB oligomerization, we crosslinked both the soluble and the membrane-bound protein with 3, 3'-Dithiobis(sulfosuccinimidyl propionate) (DTSSP), resolved it by SDS-PAGE and visualized by silver staining. Remarkably, IpaB formed oligomers of similar sizes in solution and bound to LUVs (Figure 1c). This oligomerization is reversible and depends on the LDAO concentration as shown by crosslinking (Figure 1d) and SEC (Supplementary Figure 1d) analysis. Indeed, IpaB formed oligomers in solutions below LDAO's critical micelle concentration (CMC) that dissociated into monomers when the detergent concentration was increased above the CMC. By native PAGE electrophoresis we found that IpaB formed oligomers of a constant size bigger than decamers (Supplementary Figure 1e). Noteworthy, monomers were not observed in solution in the absence of detergent micelles by any of the methods used. Together, these results demonstrate that purified IpaB spontaneously oligomerizes in solution and that these oligomers integrate and permeabilize eukaryotic membranes.

Soluble IpaB kills cells. S. flexneri-induced macrophage death requires IpaB, ${ }^{9}$ but it is unclear whether this protein is sufficient to kill cells. We show that purified IpaB is sufficient to kill bone marrow-derived macrophages (BMM) and that this effect is dose-dependent (Figure 2a). Neither the IpaB/ IpgC complex nor purified IpgC, obtained after separating it from IpaB, induced lactate dehydrogenase (LDH) release, showing that the observed cytotoxic effect was specific to IpaB (Figure 2b).

Beside cytotoxicity to BMMs, IpaB efficiently killed human monocyte-derived macrophages and human monocyte-like THP-1 cells differentiated with phorbol myristate acetate but not HeLa cells or HEK293 (Figures 2c and $d$ and Supplementary Figure 2) in a 2-h vital dye exclusion assay. We incubated HeLa cells with IpaB and monitored cell death by membrane permeabilization and Annexin $\mathrm{V}$ staining using live cell imaging. We observed that IpaB was also cytotoxic to epithelial cells, but only after $3 \mathrm{~h}$ of treatment (Supplementary Movies 1 and 2). IpaB killed BMMs derived from toll-like receptors 4 and 2 knockout mice as efficiently as wild-type (Figure 2d and Supplementary Figure 2), ruling out the possibility of a cytotoxic effect of lipopolysaccharides (LPS) and lipoproteins contaminating the toxin preparation.

IpaB cytotoxicity requires internalization. We compared the cellular localization of IpaB in BMMs and HeLa cells by immunofluorescence microscopy. IpaB was labeled using monoclonal antibody against $\operatorname{IpaB}^{25}$ (red) and plasma membrane with fluorescent cholera toxin B (green). In BMMs, IpaB is internalized within $15 \mathrm{~min}$ to vesicular-like compartments (Figure 3a, upper row). In contrast, in HeLa 

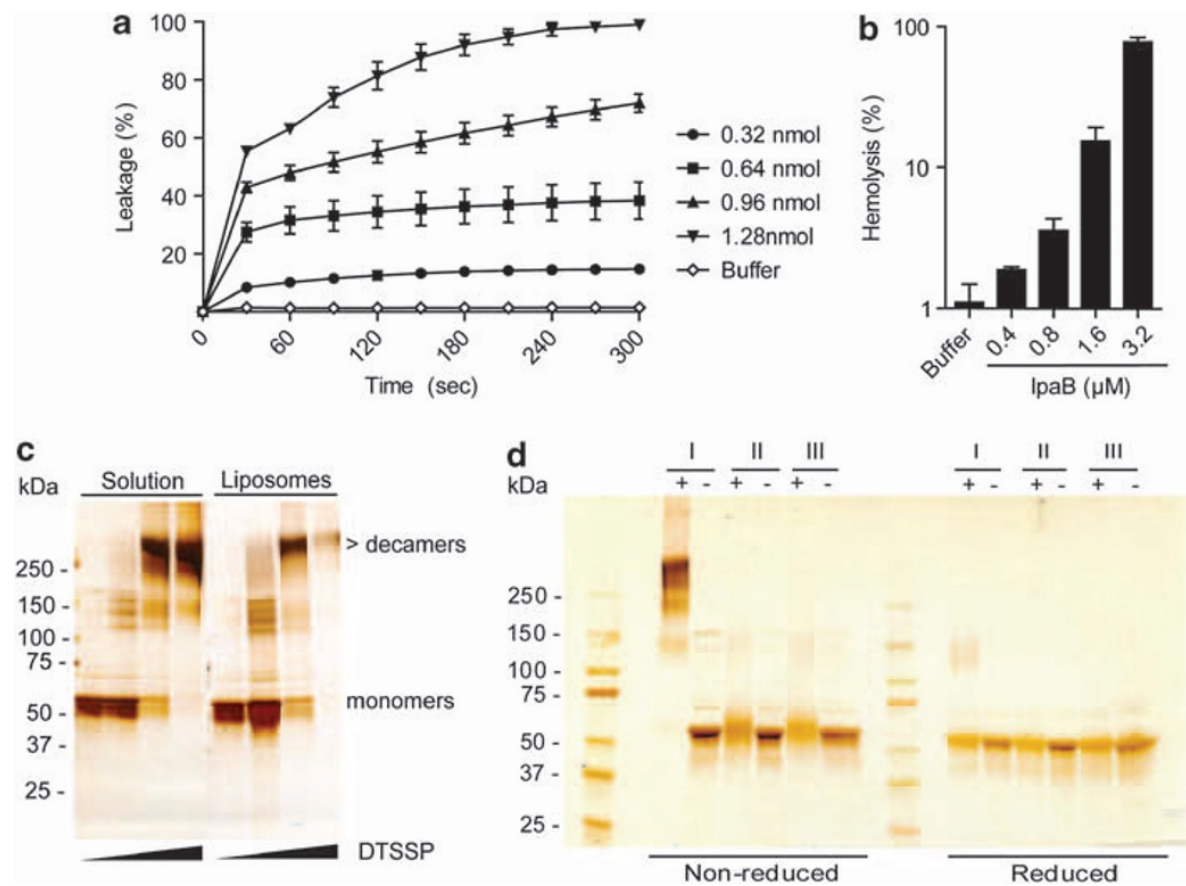

Figure 1 IpaB oligomers spontaneously integrate into eukaryotic membranes. (a) LUVs were pre-loaded with calcein and incubated with IpaB at indicated concentrations. Release of calcein was monitored for $5 \mathrm{~min}$ at $518 \mathrm{~nm}$ and plotted in percentage of Triton X-100 lysed liposomes. (b) One percent sheep RBCs were incubated with lpaB and hemolysis was followed by the increase of hemoglobin absorbance at $541 \mathrm{~nm}$ and quantified as percentage of Triton X-100 treated/ total lysed cells. In (a) and (b) values are the average of triplicates \pm S.D. (c) Oligomers of soluble and liposome-bound lpaB were detected by crosslinking for $1 \mathrm{~h}$ with $0,0.01,0.1$ or $1 \mathrm{mM}$ DTSSP and resolved under non-reducing conditions by SDS-PAGE gradient (4-15\%) and silver-stained. (d) IpaB was incubated for $1 \mathrm{~h}$ with crosslinker DTSSP (1 mM), resolved under reducing or non-reducing conditions by SDS-PAGE gradient (4-15\%) and visualized by silver stain. IpaB oligomerization was compared in the presence of: lane I, 0.0005\% LDAO, lane II, LDAO concentration reduced to $0.0005 \%$ and then brought back to $0.05 \%$ and lane III, $0.05 \%$ LDAO. Results are representative of at least three independent experiments. See also Supplementary Figure 1
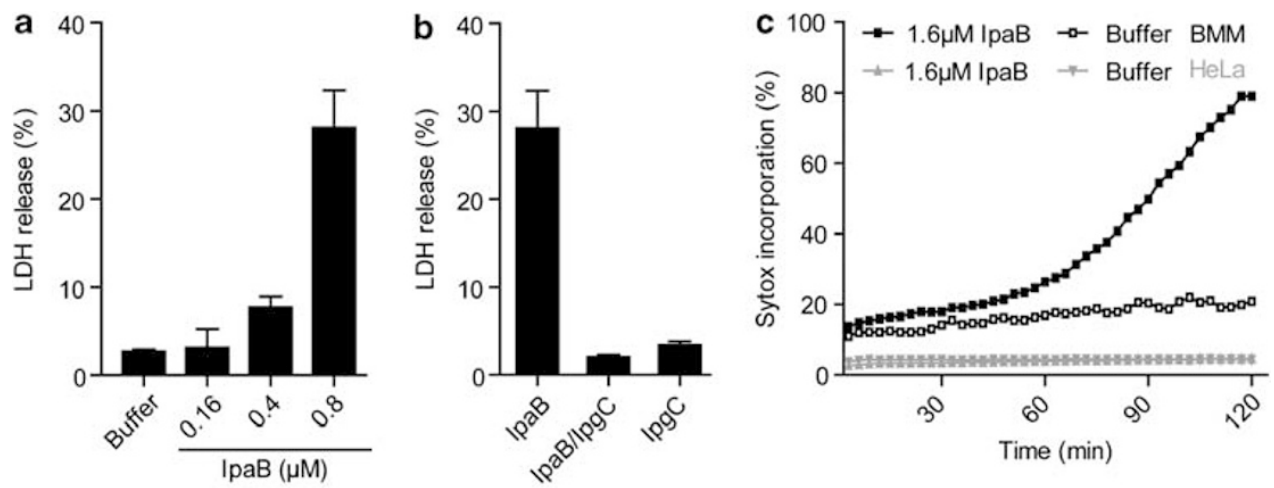

\begin{tabular}{lcc}
\hline d & Sytox incorporation (\%) & +/- s.d. (\%) \\
\hline BMM WT & 58.2 & 8.4 \\
BMM TLR2/4 KO & 72.0 & 1.8 \\
HMF & 55.3 & 5.9 \\
THP1-pma stimulated & 74.7 & 6.1 \\
HEK293 & 4.8 & 3.4 \\
HeLa & 0 & 0.4 \\
\hline
\end{tabular}

Figure $2 \mathrm{IpaB}$ kills phagocytes but not epithelial cells. (a and $\mathbf{b})$ Cytotoxicity of IpaB was quantified by measuring LDH release from macrophages after $2 \mathrm{~h}$ of treatment. Cells treated with indicated IpaB concentrations (a) or $0.8 \mu \mathrm{M} \mathrm{IpaB}$, IpaB/lpgC or IpgC (b). (c) Kinetics of IpaB cytotoxicity in BMMs and HeLa cells detected by recording fluorescence of DNA-incorporated Sytox Green (Invitrogen, Darmstadt, Germany) dye at $518 \mathrm{~nm}$ for $2 \mathrm{~h}$. (d) Cytotoxicity of IpaB expressed as \% of totally lysed cells with Triton $\mathrm{X}-100$. Cell death was detected as described in (c) and the values present cytotoxicity after $2 \mathrm{~h}$ of treatment with IpaB. Values are the average of triplicates \pm S.D. Results are representative of at least two independent experiments. See also Supplementary Figure 2 

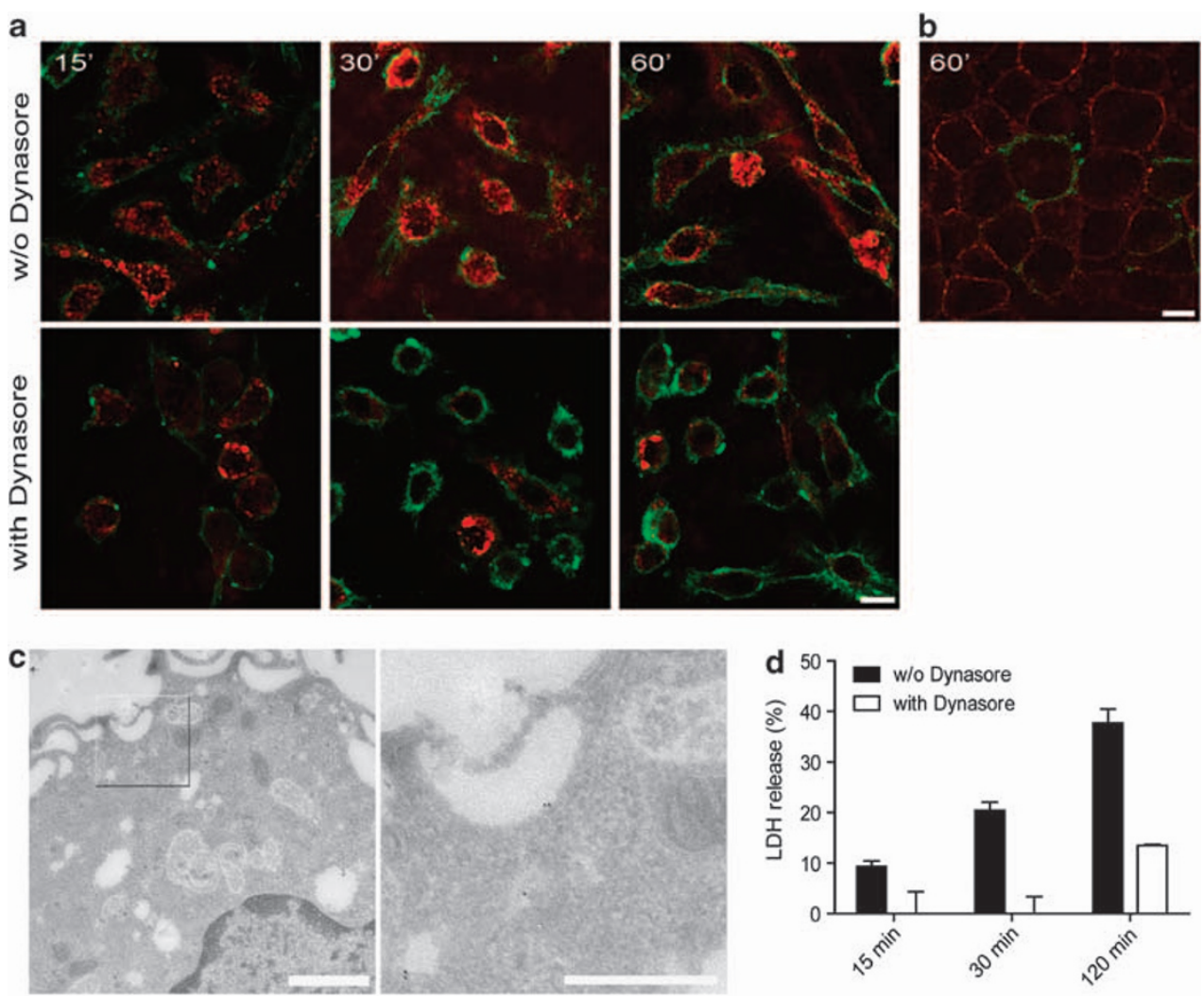

Figure $3 \mathrm{IpaB}$ uptake is essential for its cytotoxic function. (a) Immunofluorescence microscopy of IpaB $(0.8 \mu \mathrm{M})$ treated BMMs at indicated time points. IpaB was labeled using monoclonal antibody ( $\mathrm{H} 16)$ (red) and membrane is labeled using Cholera toxin subunit-B coupled to Alexa Fluor 488 (green). Upper row shows cells treated with IpaB and the lower row presents cells pre-incubated for $1 \mathrm{~h}$ with $80 \mu \mathrm{M}$ Dynasore and then treated with IpaB for indicated time intervals. Scale bar, $10 \mu \mathrm{m}$. (b) Immunofluorescence microscopy of HeLa cells after $1 \mathrm{~h}$ incubation with IpaB $(0.8 \mu \mathrm{M})$. IpaB is shown in red and plasma membrane in green. Labeling was performed as in (a). Scale bar, $10 \mu \mathrm{m}$. (c) Cryo-Immunogold Electron Microscopy of BMM after 10 min of treatment. IpaB specifically labeled with monoclonal antibody (H16) and a gold-conjugated secondary antibody showed endosomal localization. Scale bar, $1 \mu \mathrm{m}$ in the overview and $500 \mathrm{~nm}$ in the detailed insert. (d) LDH release from macrophages treated with $0.8 \mu \mathrm{M}$ IpaB without or with pre-incubation with $80 \mu \mathrm{M}$ Dynasore. Values are the average of triplicates \pm S.D. Results are representative of at least two independent experiments. See also Supplementary Figure 3

cells, IpaB localized to the cell membrane $1 \mathrm{~h}$ after the treatment (Figure $3 \mathrm{~b}$ ) and was partially internalized after $4 \mathrm{~h}$ of incubation (Supplementary Figure 3a). We next analyzed the subcellular distribution of IpaB upon endocytosis in macrophages. Notably, by immunoelectron microscopy, we showed that in BMMs IpaB is found mostly in endosome-like compartments and to a lesser extent at the cell surface after $10 \mathrm{~min}$ or $30 \mathrm{~min}$ of incubation (Figure 3c, Supplementary Figure $3 \mathrm{~b}$ and $\mathrm{c}$ ).

Interestingly, blocking internalization of IpaB in BMMs (Figure 3a, lower row) using Dynasore, an inhibitor of the small GTPase dynamin required for endocytosis, ${ }^{26}$ also abolished its cytotoxicity (Figure $3 \mathrm{~d}$ and Supplementary Figure $3 d$ ). This indicates that endocytosis of IpaB is required to cause rapid cell death.

IpaB induces leakage of lysosomes. We followed the fate of IpaB-containing vacuoles in BMMs loaded with the $\mathrm{pH}$ sensitive fluorescent dye acridine orange (AO) by live cell imaging. $\mathrm{AO}$ accumulates in acidic compartments such as late endosomes and lysosomes, and fluoresces in red. Dilution of the dye or an increase in $\mathrm{pH}$ decreases the red fluorescence and indicates endolysosomal permeabilization. In $\mathrm{BMMs}$ exposed to IpaB, red fluorescence of $\mathrm{AO}$ decreased gradually over $10 \mathrm{~min}$ (upper row in Figure $4 \mathrm{a}$ and Supplementary Movie 3). Control cells, incubated with buffer alone, did not show a change in AO-fluorescence over the same time (Figure 4a, lower row and Supplementary Movie 4).

We quantified endolysosomal leakage in AO-labeled BMMs by flow cytometry. We counted cells with decreased fluorescent emission at $670 \mathrm{~nm}$ (Figure 4b, gate $M$ ) and demonstrated that $30 \mathrm{~min}$ after treatment IpaB caused endolysosomal rupture in $40 \%$ of the cells (Figure $4 \mathrm{c}$ ).

We also tested vacuolar damage in BMMs using the fluorescently labeled fluid-phase endolysosomal marker Dextran with a molecular weight of $10 \mathrm{kDa}$ (Figure 4d). BMMs showed a punctate, green staining due to accumulation of Dextran inside endolysosomal compartments. Cells incubated with IpaB for 15 min showed a similar distribution of fluorescence due to the presence of intact endolysosomes. Thirty minutes after the treatment with IpaB, however, cells displayed a diffuse cytosolic staining indicating endolysosomal rupture and release of fluorescent Dextran into the cytosol.

These observations indicate that internalized IpaB causes permeabilization and subsequent disruption of endolysosomes in affected cells. 

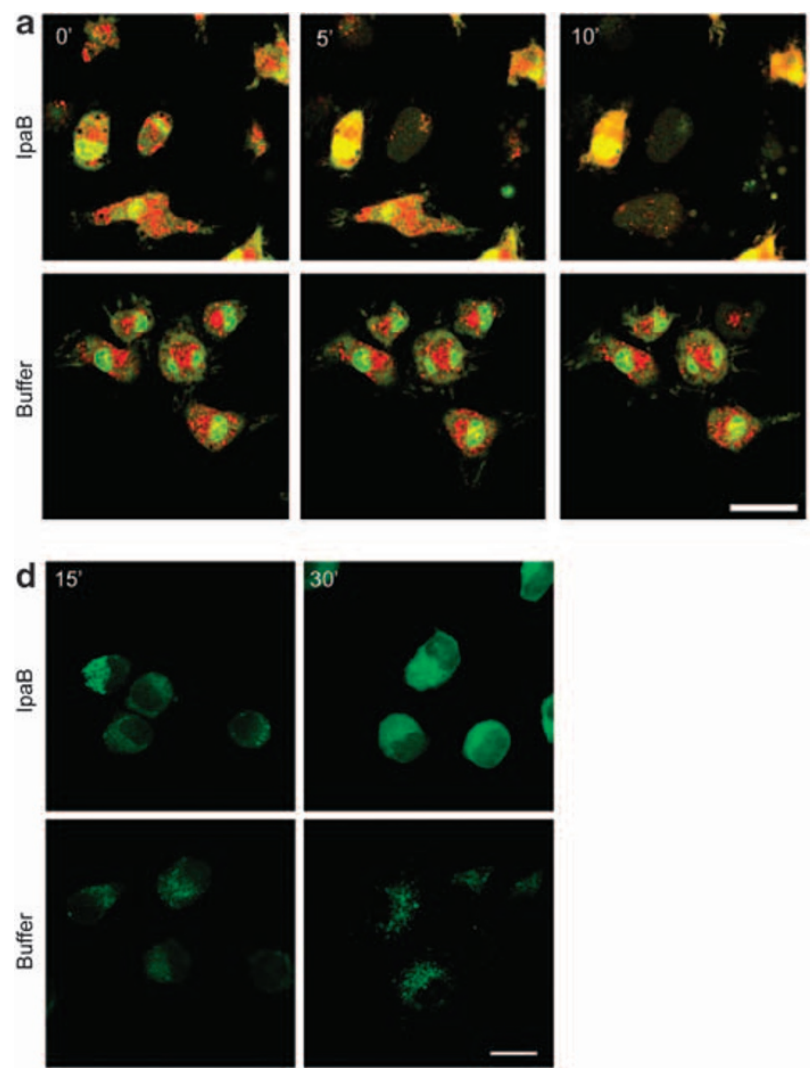
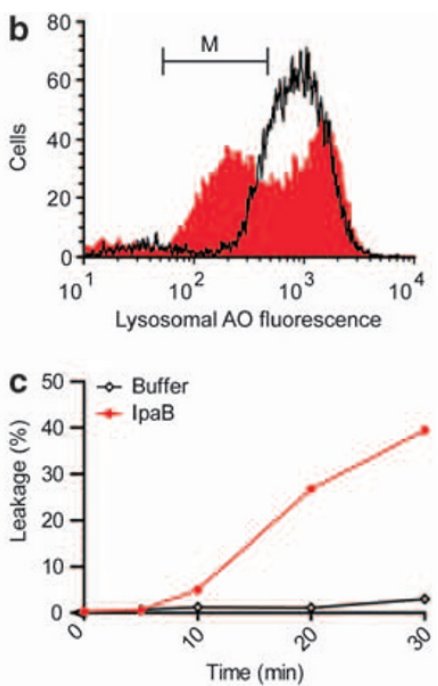

Figure $4 \mathrm{IpaB}$ induces lysosomal rupture. (a) Confocal Microscopy of BMMs labeled with $\mathrm{AO}(1 \mu \mathrm{g} / \mathrm{ml})$ (excitation at $488 \mathrm{~nm}$; emission at $650-690 \mathrm{~nm})$ and incubated with $0.8 \mu \mathrm{M} \mathrm{IpaB}$ (upper row) or buffer (lower row). Images are taken at indicated time points from live cell imaging included in Supplementary Information (see Movie S1 and S2). $\mathrm{AO}$ accumulated in lysosomes is labeled red and bound to DNA or RNA in the cytosol is labeled green. Scale bar, $10 \mu \mathrm{m}$. (b) Flow cytometry of BMM stained with AO (1 $\mu \mathrm{g} / \mathrm{ml})$ and then treated for $5,10,20$ and 30 min with $\mathrm{IpaB}(0.8 \mu \mathrm{M})$ or left untreated (buffer). AO was detected in the FL3 channel (X-axis). Histograms in red show fluorescence of cells treated with IpaB; histogram in black for untreated cells. Endolysosomal leakage was monitored by the reduction in the fluorescence of cells gated in $\mathrm{M}$. The $\mathrm{Y}$-axis presents the cells counts. (c) Quantification of cells gated in M incubated with IpaB or left untreated during 30 min as described in (b). Gated BMMs showed the endolysosomal leakage. (d) Confocal microscopy of BMMs loaded with Dextran-Alexa Fluor $488(0.1 \mathrm{mg} / \mathrm{ml})$ for $15 \mathrm{~min}$ (green) and subsequently treated with $0.8 \mu \mathrm{M}$ IpaB or buffer for indicated times. Scale bar, $10 \mu \mathrm{m}$. See also Supplementary Movies 1 and 2

IpaB forms cation selective channels within endosomes. To understand how IpaB breaks vacuoles and induces cell death we next characterized the properties of membranebound IpaB by applying a two-electrode voltage clamp (TEVC) on Xenopus laevis oocytes in the presence of purified protein. After incubation of the oocytes with IpaB we applied $25 \mathrm{mV}$ voltage steps ranging from -150 to +75 and measured the resulting electrical currents at each step. We observed increased electrical current in cells with incorporated IpaB compared with untreated cells in all membrane potentials applied (Figure $5 \mathrm{a}$ and Supplementary Information, Supplementary Figure 4). The current recorded from cells exposed to IpaB showed a simple, almost linear, $\mathrm{I} / \mathrm{V}$ relation, suggesting that the effector forms a channel that is not voltage gated. The slope of the $\mathrm{I} / \mathrm{V}$ lines indicate a conductance value of $\sim 6.2 \mu \mathrm{S}$ in treated and $\sim 1.5 \mu \mathrm{S}$ in untreated oocytes resulting in a net conductivity of $\sim 4.7 \mu \mathrm{S}$ for IpaB channels.

We performed TEVC experiments with IpaB-treated oocytes and showed that lowering the extracellular $\mathrm{pH}$ from 9.0 to 4.0 resulted in an increase of the inward-directed current measured at $-100 \mathrm{mV}$ (Figure $5 \mathrm{~b}$ ). The current amplitudes in untreated cells did not differ in this $\mathrm{pH}$ range
(Figure 5b), indicating that the ion flux measured is characteristic of IpaB.

To test the ion selectivity of the IpaB channels, we performed TEVC recordings at neutral $\mathrm{pH}$ in the presence of specific alkali metal ions and compared current amplitudes at $-100 \mathrm{mV}$. Flux of monovalent cations like $\mathrm{Li}^{+}, \mathrm{Na}^{+}, \mathrm{K}^{+}$or $\mathrm{Rb}^{+}$resulted in currents with similar amplitudes (Figure $5 \mathrm{c}$ ). No current was observed for the divalent ions $\mathrm{Mg}^{2+}$ and $\mathrm{Ca}^{2+}$ or larger single-charged ions like tetraethyl ammonium $\left(\mathrm{TEA}^{+}\right.$) or $\mathrm{N}$-methylglucamine $\left(\mathrm{NMG}^{+}\right)$. Moreover, sodium chloride and sodium aspartate display similar amplitudes, indicating that the IpaB channel does not allow the passage of negatively charged ions, such as chloride (Figure $5 \mathrm{c}$ ). These results demonstrate that IpaB forms ion channels inside eukaryotic membranes with a $\mathrm{pH}$ - dependent conductivity and a preference for small monovalent anorganic cations and protons.

We examined the effect of internalized IpaB ion channels on distribution of anorganic ions inside macrophages with quantitative electron probe X-ray microanalysis (EPXMA) ${ }^{27}$ To stimulate endocytosis, we treated BMMs with IpaB or buffer in the presence of $10 \mathrm{kDa}$ Dextran for $10 \mathrm{~min}$ and measured $\mathrm{Na}^{+}, \mathrm{K}^{+}, \mathrm{Mg}^{+2}, \mathrm{Ca}^{+2}$ and $\mathrm{Cl}^{-}$concentrations 

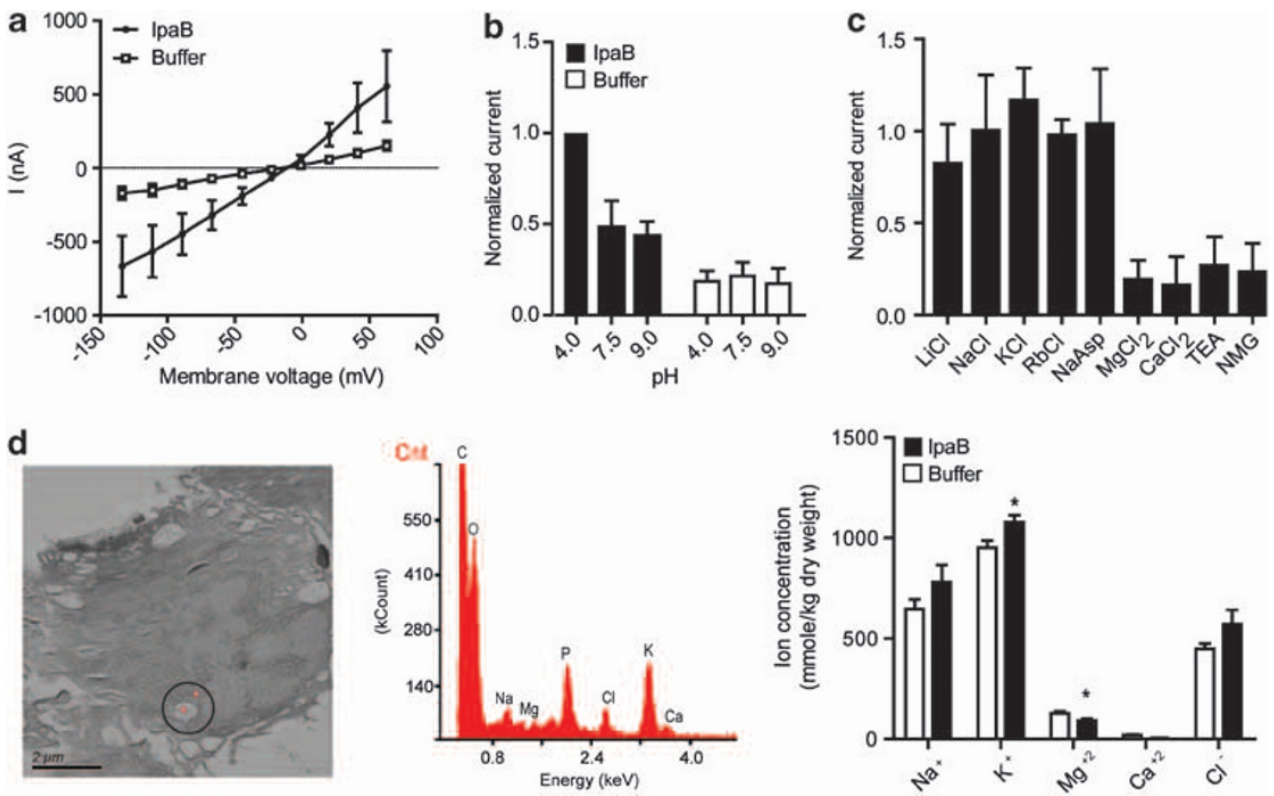

Figure 5 Characterization of the IpaB ion channels. (a) Two-electrode voltage-clamp recording presented as current-voltage relationship of $X$. laevis oocytes incubated with $1.6 \mu \mathrm{M} \mathrm{IpaB}$ for $4 \mathrm{~h}$. Cells incubated with buffer containing LDAO were used as control. (b) pH dependence of IpaB-mediated ion conductance measured at $-100 \mathrm{mV}$. Background control as in (a). (c) Current amplitudes in oocytes treated with IpaB recorded at $-100 \mathrm{mV}$ in the presence of different ions. Current values were normalized comparing with the value obtained for $\mathrm{NaCl}$. The values shown are an average of 4-6 recorded cells \pm S.D. (d) Determination of ion contents with EPXMA in cryofixed BMMs after $10 \mathrm{~min}$. Treatment with $0.8 \mu \mathrm{M} \mathrm{IpaB}$ or buffer containing LDAO. An example TEM image of a cryosectioned control cell (left panel) is shown together with a typical EPXMA spectrum used for quantification of anorganic ions (middle panel). Single measurements, indicated as red dots, were performed inside electron-light vacuole and the surrounding cytosol. The peak of emission for each anorganic ion is indicated with the element's symbol. Ion concentrations measured in the vacuoles of treated BMMs (right panel). Values are an average of 26-30 measured vacuoles \pm S.E.M. (asterisks, $P<0.05$ using Student's $t$-test). See also Supplementary Figures 4 and 5

inside the vacuoles and in the cytoplasm of cryofixed cells (Supplementary Figures $5 \mathrm{a}$ and $\mathrm{b}$ ). Cells treated with IpaB contained significantly higher $\mathrm{K}^{+}$and lower $\mathrm{Mg}^{+2}$ concentrations inside the vacuoles than the control cells. The contents of other ions tested inside vacuoles remained unchanged (Figure $5 \mathrm{~d}$ ). Concurrently in the cytosol no $\mathrm{K}^{+}$ or $\mathrm{Mg}^{+2}$ fluxes were observed, whereas $\mathrm{Na}^{+}$and $\mathrm{Cl}^{-}$ concentrations significantly decreased (Supplementary Figure 5c).

These results show that IpaB forms ion channels that promote $\mathrm{K}^{+}$flux in endosomes.

IpaB-mediated $\mathrm{K}^{+}$flux activates Caspase-1 through the IPAF inflammasome. Caspase-1 activation and induction of cell death in $S$. flexneri-infected macrophages requires IpaB secretion. ${ }^{9,28}$ Purified IpaB activated Caspase- 1 in a dose-dependent manner in LPS-primed primary macrophages as indicated by the presence of the active p10 subunit in western Blot analysis (Figure 6a). In agreement with this observation, purified IpaB induced the release of mature IL-1 $\beta$ to the supernatants in wild-type but not in Caspase-1-deficient macrophages (Figure 6b). Importantly, IpaB bound to its chaperone IpgC, as well as IpgC alone, did not cause IL-1 $\beta$ secretion (Figure $6 \mathrm{c}$ ). In addition, removal of the endotoxin contaminations by EndoTrap Red Affinity column (Profos AG, Regensburg, Germany) from purified IpaB did not affect Caspase-1 activation (data not shown). Caspase-1 activation, together with LDH release data, showed that IpaB induces an inflammatory cell death in host cells. After $2 \mathrm{~h}$ treatment with IpaB about 25\% BMMs were terminal deoxynucleotidyl transferase dUTP nick end labeling positive (Supplementary Figure 6) confirming that the host cells were indeed undergoing pyroptosis.

We stimulated immortalized macrophage cell lines from wild-type, NALP3 (NACHT, LRR and PYD domains-containing protein 3)-, IPAF- or ASC- deficient mice with IpaB and found that similar to $S$. flexneri infections ${ }^{18}$ the release of IL-1 $\beta$ from IpaB-treated macrophages required IPAF and ASC, but not NALP3 (Figure 6d). These results demonstrate that IpaB is required and is sufficient to activate the IPAF inflammasome, leading to Caspase-1 activation and secretion of mature IL- $1 \beta$ in macrophages.

Next, we tested whether IpaB-mediated $\mathrm{K}^{+}$flux is required to trigger Caspase- 1 activation in macrophages. As predicted, the presence of high $\mathrm{K}^{+}$concentration in the extracellular medium and consequently inside endosomes significantly decreased IL-1 $\beta$ secretion compared with IpaB-treated cells incubated with physiological $\mathrm{K}^{+}$concentration (Figure 6e). Importantly, raised $\mathrm{K}^{+}$concentration in the medium also inhibited IL-1 $\beta$ secretion in M90T-infected macrophages (Figure 6f). We confirmed these results by blocking $\mathrm{K}^{+}$flux with the ATP-sensitive $\mathrm{K}^{+}$-channel inhibitor glibenclamide, which completely abolished IL-1 $\beta$ release in both IpaB treated and $S$. flexneri-infected macrophages (Supplementary Figure 7). Extracellular ATP was used as a positive control as Caspase-1 activation with this stimulus depends on potassium flux.

Together these results demonstrate that during $S$. flexneri infection IpaB ion channels permit $\mathrm{K}^{+}$flux in endosomes, which is required for Caspase- 1 activation and IL-1 $\beta$ release. 

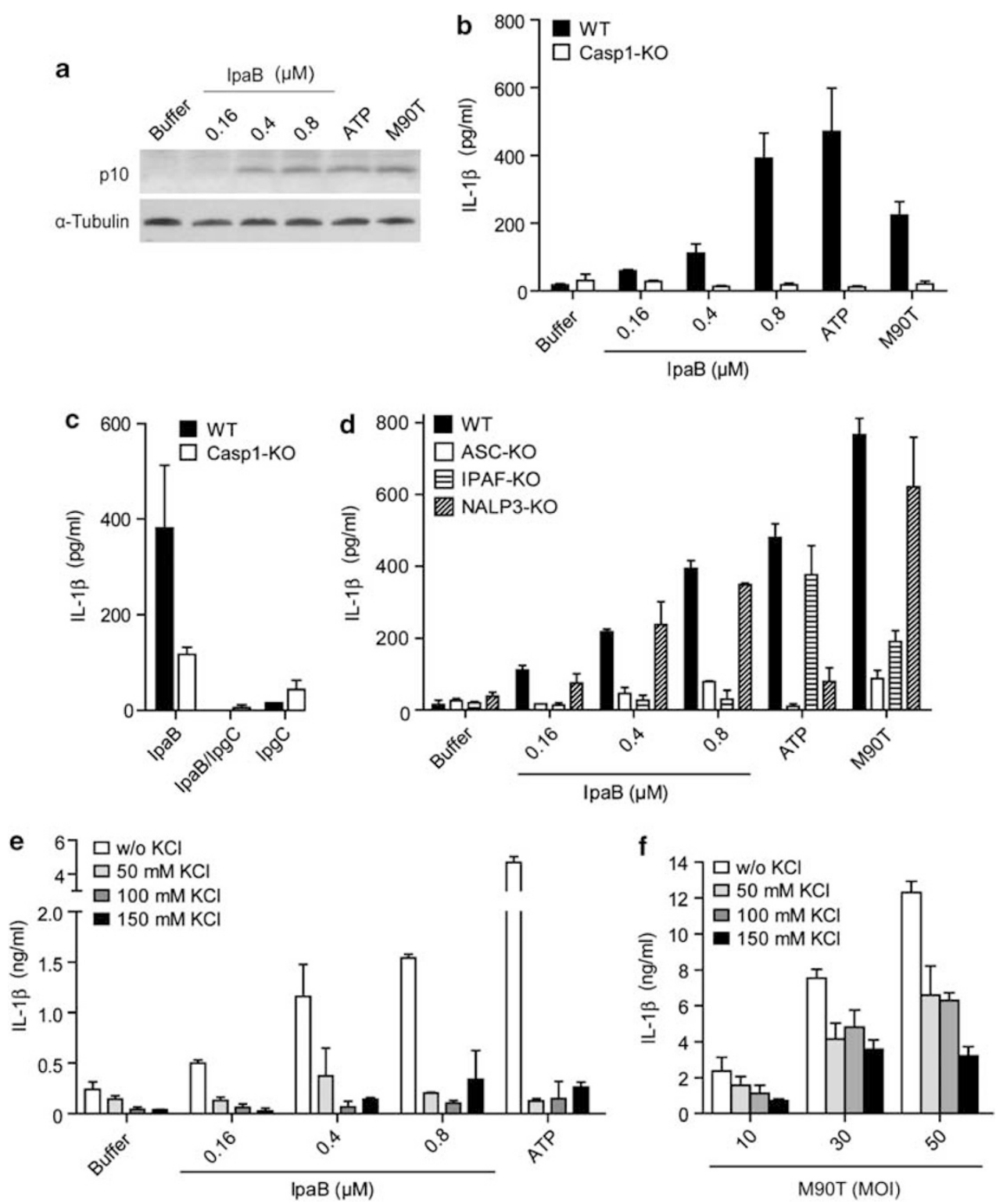

Figure 6 Purified IpaB causes Caspase-1 activation and IL-1 $\beta$ release. (a) Immunoblot analysis of the Caspase-1 maturation to the active p10 subunit in $3 \mathrm{~h} \mathrm{LPS-primed}$ macrophages treated with IpaB at the indicated concentrations for $2 \mathrm{~h}$. Treatment with ATP or Shigella were used as positive controls. Cells incubated with buffer were used as negative control and $\alpha$-Tubulin is used as loading control. (b, $\mathbf{c}$ and d) ELISA of IL-1 $\beta$ secretion by primary macrophages treated as described in (a). Wild-type (WT) and Caspase-1-deficient macrophages treated with I $\mathrm{paB}$ at the indicated concentrations. Controls were used as in the previous panel (b). Macrophages treated with $0.8 \mu \mathrm{M}$ IpaB were compared with cells treated with the same concentrations of $\mathrm{IpaB} / \mathrm{lpgC}$ and IpgC (c). IL-1 $\beta$ secretion of IpaB treated WT BMM and Caspase-1 knockout cells (Casp1-KO) is shown in (b) and (c). Treatment of WT macrophages compared with ASC-, IPAF- and NALP3-defficient cells with IpaB at indicated concentrations. ATP or Shigella stimuli were used as positive controls and buffer as negative control (d). ELISA of IL-1 $\beta$ secretion by $3 \mathrm{~h} \mathrm{LPS}$-primed macrophages macrophages treated with IpaB for $2 \mathrm{~h}(\mathbf{e})$ or infected with $S$. flexneri for $1 \mathrm{~h}(\mathrm{f})$ in the presence of different extracellular $\mathrm{KCl}$ concentrations. Treatment with buffer containing LDAO and ATP were used as controls. Values are an average of triplicates \pm S.D. Results are representative of at least three independent experiments

\section{Discussion}

The Shigella effector IpaB is an essential virulence factor with homologs in several other Gram-negative bacteria of medical importance causing typhoid fever, the plague, pneumonia or melioidosis. ${ }^{29}$ This virulence factor allows $S$. flexneri to invade host cells, to escape from phagosomes and to activate the inflammasome. The mechanism by which IpaB can fulfill all these functions is still unclear.
Although bacteria use TTSS to sense the host and to inject the effectors in the host cell, ${ }^{5}$ many of these proteins including IpaB are also secreted in the extracellular medium, ${ }^{22}$ in the bacteria-containing phagosome ${ }^{21}$ or within the host cytoplasm. ${ }^{30}$ In order to understand the function of secreted IpaB, we developed a purification procedure, which yielded a sufficient amount of folded protein for in vitro mechanistic assays. We found that purified IpaB spontaneously forms oligomers in solution. This oligomerization requires 
hydrophobic interaction between IpaB molecules, as the process can be reversed by detergent micelles.

Consistent with a previous report, ${ }^{11}$ we show that IpaB oligomers permeabilize host membranes. Importantly, TEVC measurements of IpaB in Xenopus oocyte membranes showed that it forms channels specifically transporting monovalent cations and protons. These channels are constitutively open and not voltage gated and, remarkably, transport cations most effectively at an acidic $\mathrm{pH}$.

We show that IpaB channels must be internalized by endocytosis to kill macrophages. Endocytosis and the increasing cationic flux at acidic $\mathrm{pH}$ suggested that IpaB works in phagocytic compartments. By measuring the ion contents within the endosomes with EPXMA after the treatment of cells with IpaB, we showed that IpaB channels permit a flux of potassium ions in the vacuole according to the established gradients across vacuolar membranes. We assume that the $\mathrm{Mg}^{2+}$ flux in endosomes was the consequence of an ion imbalance and was not conducted through IpaB ion channels, as our TEVC measurements showed that IpaB does not transport magnesium ions. We speculate that the observed decrease in $\mathrm{Na}^{+}$and $\mathrm{Cl}^{-}$ concentrations inside the cytoplasm is most likely a response of BMMs to IpaB treatment, as these ions are transported against the concentration gradient. As shown earlier these could be an early event in pyroptosis. ${ }^{31}$

The integrity of endocytic vacuoles depends on tightly regulated osmotic homeostasis, which is maintained by limited permeability for ions and protons. Potassium homeostasis has important role in preserving lysosomal integrity and uncontrolled $\mathrm{K}^{+}$influx due to low temperature, loss of membrane cholesterol or lysosomal membrane oxidation and that can lead to increased osmotic pressure and rupture of the vacuoles. ${ }^{32-34}$ Therefore, constitutively open IpaB channels, disturbing the ionic homeostasis of acidified vacuoles, may affect endolysosomal integrity. Vacuolar damage is supported by experiments presented here showing that IpaB-containing vacuoles release fluorescent markers. Whether IpaB channel formation affects the ionic balance and integrity of other compartments remains to be determined.

Some bacterial pathogens evolved a mechanism to disrupt the integrity of bacterium-containing phagosome by secreted bacterial PFTs assembling large pores in host cell membranes. ${ }^{35,36}$ Lysteriolysin, a PFT secreted by Listeria monocytogenes, disrupts an ion gradient across vacuolar membranes leading to a delayed maturation and finally the disintegration of bacterium-containing vacuoles. ${ }^{36}$ Similarly, IpaB secreted from phagocytosed bacteria was suggested to cause vacuolar membrane destabilization in macrophages and epithelial cells allowing $S$. flexneri to escape from the phagosome. ${ }^{12}$ Hume et al. ${ }^{37}$ suggested that $S$. flexneri may require an additional bacterial factor for phagosomal membrane lysis as they did not observe liposome or erythrocyte lysis with purified IpaB. Notably, their purification strategy did not include detergents and raises the questions whether IpaB purified by these authors was properly folded and fully functional. Our results are, however, consistent with earlier results ${ }^{11}$ and show that IpaB alone is sufficient to cause vacuolar rupture in host cells.
Stimuli like PFTs, silica and uric acid crystals, are known to permeabilize the lysosomal membrane. ${ }^{35}$ Membrane destabilization and the release of lysosomal proteases, for example Cathepsins, into the cytosol are thought to promote cell death. ${ }^{36,38}$ We propose that the vacuolar damage induced by IpaB channels, either endocytosed from extracellular $S$. flexneri supernatant or released in phagolysosomal membranes, might trigger macrophage death.

We show that Caspase-1 activation induced by purified IpaB requires the IPAF/ASC inflammasome, but not NALP3 inflammasome. Our results demonstrate that potassium flux is required for Caspase-1 activation and suggest this could be the unknown signal for IPAF inflammasome activation. Interesting questions remain whether the potassium flux in the vacuole is sensed by the IPAF inflammasome or the downstream effects are required for its activation.

Supplementary Figure 8 shows a model consistent with our data describing uptake and killing of phagocytic cells by IpaB. IpaB released from Shigella in the vicinity of a targeted cell can oligomerize spontaneously (I) before it may integrate in host membranes (II). IpaB channels, specific for small monovalent cations, are internalized in a dynamin-dependent process (III). Lysosomes or phagolysosomes, destabilized by membranebound IpaB, may release their content, most likely due to potassium influx and the impaired ionic homeostasis (IV). Lysosomal contents released from collapsing vacuoles or potassium flux by itself may induce the formation of IPAF/ ASC-inflammasomes and finally death of the infected cell $(\mathrm{V})$.

IpaB homologs from S. typhimurium, ${ }^{39}$ Burkholderia pseudomallei, ${ }^{40} P$. aeruginosa ${ }^{41}$ and Yersinia enterocolitica ${ }^{42}$ also activate Caspase-1 and induce host cell death. Potassium efflux is important to trigger IPAF inflammasome activation both in $P$. aeruginosa and $S$. typhimurium ${ }^{41}$ but the mechanism of activation remains unknown. Considering the sequence similarity and related functions, the model suggested here could be relevant for orthologous translocator proteins from other enteropathogenic bacteria using TTSS for infection.

In summary, we show that IpaB forms ion channels in eukaryotic membranes that are selective for monovalent cations. Internalization of the IpaB channels and potassium influx is followed by endolysosomal leakage, Caspase-1 activation, and macrophage cell death. It is interesting to speculate that IpaB and its functional homologs in other pathogenic enterobacteria represent a new class of cation channels essential for bacterial virulence. This finding should enable mechanistic and structural studies to explore how translocator proteins could conduct ions, and how we can block ion transport and inhibit bacterial infections dependent on TTSS.

\section{Materials and Methods}

Cell culture. HeLa cells, THP-1 and HEK293 were from Deutsche Sammlung von Mikroorganismen und Zellkulturen $\mathrm{GmbH}$.

Peripheral blood mononuclear cells (PBMC) were isolated from venous blood of healthy adult volunteers by Ficoll-Paque (Pharmacia Biotech, Uppsala, Sweden) density gradient centrifugation as recommended by the manufacturer. Monocytes were isolated from PBMC by Magnetic Activated Cell Sorting method with the Monocyte Isolation Kit II (Miltenyi Biotec, Bergisch-Gladbach, Germany). Isolated monocytes were differentiated in macrophages for 6 days in RPMl1640 medium containing $5 \%$ human serum, $10 \mathrm{mM}$ L-glutamine, and $5 \mathrm{ng} / \mathrm{ml}$ of macrophagecolony stimulating factor. 
Peritoneal macrophages were elicited using $4 \%$ (w/v) thioglycolate solution, collected by peritoneal lavage 4 days later ${ }^{43}$ and prepared as described earlier. ${ }^{44}$ Bone marrowderived macrophages were prepared as described. ${ }^{45}$ Immortalized macrophage cell lines from wild-type, NALP3-, IPAF- or ASC- deficient mice were kindly provided by Eicke Latz (University of Massachusetts Medical School, Worcester).

Caspase-1 activity assay. Macrophages were primed for $3-5 \mathrm{~h}$ with LPS from S. typhimurium (Alexis, New York, NY, USA) $(2 \mu \mathrm{g} / \mathrm{ml})$, stimulated for $2 \mathrm{~h}$ with purified proteins, $2 \mathrm{mM}$ ATP (Roche, Mannheim, Germany) or $1 \mathrm{~h}$ with $S$. flexneri and IL- $1 \beta$ levels were measured in supernatants with ELISA kit from BD Biosciences (Heidelberg, Germany) according to the manufacturer's instructions. For experiments involving manipulations of extracellular potassium concentrations, priming was performed in OptiMEM medium and $\mathrm{K}^{+}$concentrations were increased $30 \mathrm{~min}$ before $\mathrm{IpaB}$ treatment or $\mathrm{S}$. flexneri infection.

Cell death assays. LDH release assay was performed as previously described $^{39}$ using the CytoTox 96 kit (Promega, Mannheim, Germany) following the manufacturer's instructions.

Kinetics of cytotoxicity was detected by measuring increase of fluorescence of SYTOX Green Nucleic Acid Stain (Molecular probes, Invitrogen, Darmstadt, Germany) after incorporation into DNA at $518 \mathrm{~nm}$ using Fluoroskan Ascent FL, Thermo Labsystems, Waltham, MA, USA.

Hemolysis. One percent sheep RBCs in phosphate buffer saline (PBS) (Labor Dr Merk \& Kollegen GMBH) were treated at $37^{\circ} \mathrm{C}$ for $1 \mathrm{~h}$. Absorbance of released hemoglobin was measured at $540 \mathrm{~nm}$.

Flow cytometry. BMMs were incubated for $15 \mathrm{~min}$ with $\mathrm{AO}$ (Molecular Probes, Invitrogen) $(1 \mu \mathrm{g} / \mathrm{ml})$, washed three times and then stimulated with $\mathrm{lpaB}$. Lysosomal rupture was assessed as loss of emission at $600-650 \mathrm{~nm}$ by FACSCalibur (BD Biosciences). Data were acquired and analyzed by BD CellQuest Pro Software (BD Biosciences).

Liposome leakage assay. Mixture containing $40 \% \mathrm{~L}-\alpha-P C$ (from egg yolk), $10 \% \mathrm{~L}-\alpha-\mathrm{PS}$ (from porcine brain), $25 \% \mathrm{~L}-\alpha-\mathrm{PE}$ (from porcine brain), $15 \% \mathrm{SM}$ (from porcine brain) and 10\% L- $\alpha-\mathrm{PI}$ (from bovine liver) (Avanti Polar Lipids Inc., Alabaster, AL, USA) (w/w) was dissolved in chloroform and was dried under a stream of nitrogen followed by overnight vacuum drying. LUVs with a diameter of $0.4 \mu \mathrm{m}$ were prepared using an extruder (Avestin Europe $\mathrm{GmbH}$., Mannheim, Germany) according to Hope et al. ${ }^{46}$ Accordingly, LUVs containing $50 \mathrm{mM}$ calcein (Molecular Probes, Invitrogen) were prepared. The non-encapsulated dye was removed from the liposome suspension by ultracentrifugation. The osmolarity of the solution (calcein and buffer) was measured with an Osmomat 030, Gonotec $\mathrm{GmbH}$ (Berlin, Germany).

Liposome leakage assay was performed in 96-well plate with $30 \mathrm{nmol}$ LUV suspension added per well and calcein release was recorded by measuring the fluorescence at excitation and emission wavelengths of 485 and $518 \mathrm{~nm}$, respectively at $37^{\circ} \mathrm{C}$ using Fluoroskan Ascent FL, Thermo Labsystems. The percentage of fluorescence $F_{t}$ at time $t$ is defined as: $\% F_{t}=\left(I_{t}-I_{0} / I_{t}-I_{0}\right) \times 100$ where $I_{0}$ is the initial fluorescence obtained after the dilution of the vesicles in the appropriate buffer, $I_{\mathrm{f}}$ is the total fluorescence observed after addition of Triton $\mathrm{X}-100$, and $l_{\mathrm{t}}$ is the fluorescence at time $\mathrm{t}$ corrected for the dilution.

Chemical crosslinking. Liposomes containing $P C$ and $P S(P C / P S=8 / 2)$ (Avanti Polar Lipids, Inc.) (w/w) were produced. IpaB was incubated with liposomes in PBS buffer $(\mathrm{pH}=7.4)$ for $30 \mathrm{~min}$ and non-incorporated protein removed by ultracentrifugation. Soluble $\mathrm{IpaB}$ or lipid-bound protein was crosslinked with $1 \mathrm{mM}$ DTSSP (Pierce Biotechnology, Rockford, IL, USA) at room temperature for $1 \mathrm{~h}$. Reaction was quenched with $50 \mathrm{mM}$ Tris $\mathrm{pH} 7.5$ for $30 \mathrm{~min}$.

Electrophysiology. Oocytes from Xenopus laevis were obtained from Ecocyte Bioscience (Castrop-Rauxel, Germany) and stored at $4^{\circ} \mathrm{C}$ in $\mathrm{OR}$ solution $\left(96 \mathrm{mM} \mathrm{NaCl}, 2 \mathrm{mM} \mathrm{KCl}, 1.8 \mathrm{mM} \mathrm{CaCl}, 1 \mathrm{mM} \mathrm{MgCl}_{2}, 5 \mathrm{mM}\right.$ MOPS-NaOH, pH 7.5) in the presence of $5 \mathrm{mM}$ Na-pyruvate, $50 \mu \mathrm{g} / \mathrm{ml}$ gentamicin TEVC measurements on oocytes were performed by using a GeneClamp 500 amplifier (Axon Instruments, Union City, CA, USA) or a Turbo Tec-05X (NPI Electronic, Tamm, Germany) controlled with PCLAMP software via DigiData 1322A or 1440A interfaces (Molecular devices, Sunnyvale, CA, USA).
$\mathrm{pH}$-dependency of IpaB channels was measured in solutions containing $100 \mathrm{mM}$ $\mathrm{NaCl}, 1 \mathrm{mM} \mathrm{MgCl}$ and $0.1 \mathrm{mM} \mathrm{CaCl}_{2}$ buffered with $5 \mathrm{mM}$ glycine $(\mathrm{pH} 9.0), 5 \mathrm{mM}$ Mops- $\mathrm{NaOH}(\mathrm{pH} 7.5)$ or $5 \mathrm{mM}$ citrate $(\mathrm{pH} 4.0)$. For testing cation selectivity of the channel bath solution contained $100 \mathrm{mM} \mathrm{LiCl}, 100 \mathrm{mM} \mathrm{NaCl}, 100 \mathrm{mM} \mathrm{KCl}, 70 \mathrm{mM}$ $\mathrm{MgCl}_{2}, 70 \mathrm{mM} \mathrm{CaCl}, 100 \mathrm{mM}$ TEACl or $100 \mathrm{mM} \mathrm{NMGCl}$ respectively, with $1 \mathrm{mM} \mathrm{MgCl}_{2}, 0.1 \mathrm{mM} \mathrm{CaCl}_{2}$ and $5 \mathrm{mM}$ Mops-NaOH (pH 7.5). Conductivity of $\mathrm{Cl}^{-}$ was examined after replacement of $100 \mathrm{mM} \mathrm{NaCl}$ with $100 \mathrm{mM} \mathrm{NaAspartate}$ ( $\mathrm{NaAsp}$ ) in the presence of $1 \mathrm{mM} \mathrm{MgCl}_{2}, 0.1 \mathrm{mM} \mathrm{CaCl}_{2}$ and $5 \mathrm{mM} 3$-(N-morpholino) propanesulfonic acid (Mops)- $\mathrm{NaOH}$ (pH 7.5).

Electron probe X-ray microanalysis. Ion concentrations inside endosomes and cytoplasm were measured by X-ray microanalysis on snap-frozen, freeze-dried cells. BMMs were incubated with IpaB or buffer and $10 \mathrm{kDa}$ DextranAlexa Fluor 565 (Molecular Probes, Invitrogen) for $10 \mathrm{~min}$; drops of the thick cell pellet were collected on a piece of Millipore filter paper and cryofixed by plunging them into liquid propane. The cryofixed pellets were stored under liquid nitrogen. EPXMA, spectra processing and quantification were performed as described. ${ }^{31}$ Higher absolute sodium values could be influenced by continuum estimation in the quantification routine. ${ }^{47}$

Statistical evaluation. Data are presented as the mean \pm S.E.M. Student's $t$-test was used to evaluate the statistical significance of the differences between means; a value of $P<0.05$ was considered statistically significant.

Fluorescence microscopy. BMMs and HeLa cells were grown on coverslips and treated with IpaB for indicated time. Following fixation with $4 \%$ paraformaldehyde, membrane was labeled with Cholera Toxin subunit-B coupled with Alexa Fluor 488 (Invitrogen), permeabilized with $0.1 \%$ Triton X-100, and labeled with primary anti-IpaB monoclonal antibody $(\mathrm{H} 16)$ followed by Cy5-labeled secondary antibodies (GE Healthcare, München, Germany). To follow endocytosis and endolysosomal damage, cells were coincubated with Alexa Fluor 647conjugated dextran as described elsewhere. ${ }^{38}$ The samples were analyzed on a Leica SP5 confocal microscope (Leica Microsystems, Wetzlar, Germany).

Electron microscopy. Macrophages were fixed with $1 \%$ paraformaldehyde and $0.5 \%$ glutaraldehyde in stabilising buffer (1 mM EGTA, 4\% PEG 6000 (8000), $100 \mathrm{mM}$ PIPES pH 6.9), and embedded in $10 \%$ gelatine/PBS. Small blocks of the samples were infiltrated overnight in $2.3 \mathrm{M}$ sucrose/0.1 M Na-phosphate buffer. Ultrathin sections were reacted with the anti-IpaB monoclonal antibody $(\mathrm{H} 16)$ and secondary antibodies coupled with $12 \mathrm{~nm}$ gold particles.

Immunoblot analysis. Macrophages were lysed in buffer containing $1 \%$ Nonidet-P40 supplemented with complete protease inhibitor 'cocktail' (Roche). The protein concentration was measured with BCA protein assay reagent (Pierce) and lysates were adjusted accordingly. Lysates were boiled $5 \mathrm{~min}$ with SDS sample buffer under reducing conditions, resolved by SDS-PAGE and transferred to nitrocellulose membranes by electroblotting. Active Caspase-1 was visualized using rabbit antibody to mouse Caspase-1 (sc-514, Santa Cruz Biotechnology, Santa Cruz, CA, USA).

\section{Conflict of Interest}

The authors declare no conflict of interest.

Acknowledgements. We thank Alice Warley for the help with EPXMA, Peter Jungblut and Monika Schmid for mass spectrometry analysis, Eicke Latz for providing macrophage cell lines, Armelle Phallipon and Robert Hurwitz for providing anti-IpaB antibodies, Juana de Diego, Ravi L Kumar and Peter Hegemann for helpful discussion, Juana de Diego, Anna Brotcke and Catherine Caput for their comments and critical reading of the manuscript.

\section{Author contributions}

LS established protein purification, designed and performed experiments, analyzed data and wrote the manuscript, ST performed TEVC measurements and analyzed the data, CG contributed with Immuno-EM, VB contributed with live-cell imaging, AZ designed experiments and contributed to writing this manuscript, FM designed experiments, contributed with Caspase-1 activation assays and EPXMA experiments, MK designed experiments, performed MALLS and EPXMA experiments, analyzed data and wrote the manuscript. 
1. Kotloff KL, Winickoff JP, Ivanoff B, Clemens JD, Swerdlow DL, Sansonetti PJ et al. Global burden of Shigella infections: implications for vaccine development and implementation of control strategies. Bull World Health Organ 1999; 77: 651-666.

2. Maurelli AT, Sansonetti PJ. Genetic determinants of Shigella pathogenicity. Annu Rev Microbiol 1988; 42: 127-150.

3. Zychlinsky A, Prevost MC, Sansonetti PJ. Shigella flexneri induces apoptosis in infected macrophages. Nature 1992; 358: 167-169.

4. Sansonetti PJ, Phalipon A, Arondel J, Thirumalai K, Banerjee S, Akira S et al. Caspase-1 activation of IL-1beta and IL-18 are essential for Shigella flexneri-induced inflammation. Immunity 2000; 12: 581-590.

5. Watarai M, Tobe T, Yoshikawa M, Sasakawa C. Contact of Shigella with host cells triggers release of Ipa invasins and is an essential function of invasiveness. Embo $J$ 1995; 14 : 2461-2470.

6. Lunelli M, Lokareddy RK, Zychlinsky A, Kolbe M. IpaB-IpgC interaction defines binding motif for type III secretion translocator. Proc Natl Acad Sci USA 2009; 106: 9661-9666.

7. Page AL, Ohayon H, Sansonetti PJ, Parsot C. The secreted IpaB and IpaC invasins and their cytoplasmic chaperone IpgC are required for intercellular dissemination of Shigella flexneri. Cell Microbiol 1999; 1: 183-193.

8. Menard R, Sansonetti PJ, Parsot C. Nonpolar mutagenesis of the ipa genes defines IpaB, IpaC, and IpaD as effectors of Shigella flexneri entry into epithelial cells. J Bacteriol 1993; 175: 5899-5906.

9. Zychlinsky A, Kenny B, Menard R, Prevost MC, Holland IB, Sansonetti PJ. IpaB mediates macrophage apoptosis induced by Shigella flexneri. Mol Microbiol 1994; 11: 619-627.

10. Blocker A, Gounon P, Larquet E, Niebuhr K, Cabiaux V, Parsot C et al. The tripartite type III secreton of Shigella flexneri inserts IpaB and IpaC into host membranes. J Cell Biol 1999; 147: 683-693.

11. De Geyter C, Wattiez R, Sansonetti P, Falmagne P, Ruysschaert JM, Parsot $C$ et al. Characterization of the interaction of IpaB and IpaD, proteins required for entry of Shigella flexneri into epithelial cells, with a lipid membrane. Eur J Biochem 2000; 267: 5769-5776.

12. High N, Mounier J, Prevost MC, Sansonetti PJ. IpaB of Shigella flexneri causes entry into epithelial cells and escape from the phagocytic vacuole. EMBO J 1992; 11: 1991-1999.

13. Martinon F, Mayor A, Tschopp J. The inflammasomes: guardians of the body. Annu Rev Immunol 2009; 27: 229-265.

14. Martinon F, Burns $K$, Tschopp J. The inflammasome: a molecular platform triggering activation of inflammatory caspases and processing of prolL-beta. Mol Cell 2002; 10: 417-426.

15. Broz P, Newton K, Lamkanfi M, Mariathasan S, Dixit VM, Monack DM. Redundant roles for inflammasome receptors NLRP3 and NLRC4 in host defense against Salmonella. $J$ Exp Med 2010; 207: 1745-1755.

16. Amer A, Franchi L, Kanneganti TD, Body-Malapel M, Ozoren N, Brady G et al. Regulation of Legionella phagosome maturation and infection through flagellin and host Ipaf. J Biol Chem 2006; 281: 35217-35223.

17. Franchi L, Stoolman J, Kanneganti TD, Verma A, Ramphal R, Nunez G. Critical role for Ipaf in Pseudomonas aeruginosa-induced caspase-1 activation. Eur J Immunol 2007; 37: 3030-3039.

18. Suzuki T, Franchi L, Toma $C$, Ashida H, Ogawa M, Yoshikawa $Y$ et al. Differential regulation of caspase-1 activation, pyroptosis, and autophagy via Ipaf and ASC in Shigellainfected macrophages. PLoS Pathog 2007; 3: e111.

19. Franchi L, Amer A, Body-Malapel M, Kanneganti TD, Ozoren N, Jagirdar R et al. Cytosolic flagellin requires Ipaf for activation of caspase-1 and interleukin 1beta in salmonellainfected macrophages. Nat Immunol 2006; 7: 576-582.

20. Miao EA, Alpuche-Aranda CM, Dors M, Clark AE, Bader MW, Miller SI et al. Cytoplasmic flagellin activates caspase-1 and secretion of interleukin 1beta via Ipaf. Nat Immunol 2006; 7: $569-575$.

21. Thirumalai K, Kim KS, Zychlinsky A. IpaB, a Shigella flexneri invasin, colocalizes with interleukin-1 beta-converting enzyme in the cytoplasm of macrophages. Infect Immun 1997; 65: 787-793

22. Menard R, Sansonetti $P$, Parsot $C$, Vasselon $T$. Extracellular association and cytoplasmic partitioning of the IpaB and IpaC invasins of S. flexneri. Cell 1994; 79: 515-525.

23. Birket SE, Harrington AT, Espina M, Smith ND, Terry CM, Darboe N et al. Preparation and characterization of translocator/chaperone complexes and their component proteins from Shigella flexneri. Biochemistry 2007; 46: 8128-8137.

24. Sansonetti PJ, Ryter A, Clerc P, Maurelli AT, Mounier J. Multiplication of Shigella flexneri within HeLa cells: lysis of the phagocytic vacuole and plasmid-mediated contact hemolysis. Infect Immun 1986; 51: 461-469.

25. Barzu S, Nato F, Rouyre S, Mazie JC, Sansonetti P, Phalipon A. Characterization of B-cell epitopes on IpaB, an invasion-associated antigen of Shigella flexneri: identification of an immunodominant domain recognized during natural infection. Infect Immun 1993; 61: 3825-3831.

26. Macia E, Ehrlich M, Massol R, Boucrot E, Brunner C, Kirchhausen T. Dynasore, a cell-permeable inhibitor of dynamin. Dev Cell 2006; 10: 839-850.

27. Morgan AJ, Winters C, Sturzenbaum S. X-ray microanalysis techniques. Methods Mol Biol 1999; 117: 245-276.

28. Schroeder GN, Jann NJ, Hilbi H. Intracellular type III secretion by cytoplasmic Shigella flexneri promotes caspase-1-dependent macrophage cell death. Microbiology 2007; 153: 2862-2876.

29. Coburn B, Sekirov I, Finlay BB. Type III secretion systems and disease. Clin Microbiol Rev 2007; 20: 535-549.

30. Iwai H, Kim M, Yoshikawa $Y$, Ashida H, Ogawa M, Fujita $Y$ et al. A bacterial effector targets Mad2L2, an APC inhibitor, to modulate host cell cycling. Cell 2007; 130: 611-623.

31. Arrebola F, Fernandez-Segura E, Campos A, Crespo PV, Skepper JN, Warley A. Changes in intracellular electrolyte concentrations during apoptosis induced by UV irradiation of human myeloblastic cells. Am J Physiol Cell Physiol 2006; 290: C638-C649.

32. Deng D, Jiang N, Hao SJ, Sun H, Zhang GJ. Loss of membrane cholesterol influences lysosomal permeability to potassium ions and protons. Biochim Biophys Acta 2009; 1788: 470-476.

33. Yao J, Zhang GJ. Lysosomal destabilization via increased potassium ion permeability following photodamage. Biochim Biophys Acta 1997; 1323: 334-342.

34. Reijngoud DJ, Tager JM. The permeability properties of the lysosomal membrane. Biochim Biophys Acta 1977; 472: 419-449.

35. Boya P, Kroemer G. Lysosomal membrane permeabilization in cell death. Oncogene 2008; 27: $6434-6451$.

36. Stoka V, Turk V, Turk B. Lysosomal cysteine cathepsins: signaling pathways in apoptosis. Biol Chem 2007; 388: 555-560.

37. Hume PJ, McGhie EJ, Hayward RD, Koronakis V. The purified Shigella IpaB and Salmonella SipB translocators share biochemical properties and membrane topology. Mol Microbiol 2003; 49: 425-439.

38. Hornung V, Bauernfeind F, Halle A, Samstad EO, Kono H, Rock KL et al. Silica crystals and aluminum salts activate the NALP3 inflammasome through phagosomal destabilization. Nat Immunol 2008; 9: 847-856.

39. Hersh D, Monack DM, Smith MR, Ghori N, Falkow S, Zychlinsky A. The Salmonella invasin SipB induces macrophage apoptosis by binding to caspase-1. Proc Natl Acad Sci USA 1999; 96: 2396-2401.

40. Suparak S, Kespichayawattana W, Haque A, Easton A, Damnin S, Lertmemongkolchai G et al. Multinucleated giant cell formation and apoptosis in infected host cells is mediated by Burkholderia pseudomallei type III secretion protein BipB. J Bacteriol 2005; 187: 6556-6560.

41. Arlehamn CS, Petrilli V, Gross O, Tschopp J, Evans TJ. The role of potassium in inflammasome activation by bacteria. J Biol Chem 285: 10508-10518.

42. Shin H, Cornelis GR. Type III secretion translocation pores of Yersinia enterocolitica trigger maturation and release of pro-inflammatory IL-1beta. Cell Microbiol 2007; 9: 2893-2902.

43. Hopper KE. Kinetics of macrophage recruitment and turnover in peritoneal inflammatory exudates induced by Salmonella or thioglycollate broth. J Leukoc Biol 1986; 39: 435-446.

44. Meissner F, Molawi K, Zychlinsky A. Superoxide dismutase 1 regulates caspase-1 and endotoxic shock. Nat Immunol 2008; 9: 866-872.

45. Riddles PW, Blakeley RL, Zerner B. Reassessment of Ellman's reagent. Methods Enzymol 1983; 91: 49-60.

46. Hope MJ, Bally M, Webb G, Cullis PR. Production of large unilamellar vesicles by a rapid extrusion procedure. Characterization of size distribution, trapped Volume and ability to maintain a membrane potential. Biochim Biophys Acta 1985; 812: 65.

47. Di Francesco A, Desnoyer RW, Covacci V, Wolf FI, Romani A, Cittadini A et al. Changes in magnesium content and subcellular distribution during retinoic acid-induced differentiation of HL60 cells. Arch Biochem Biophys 1998; 360: 149-157.

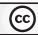

Cell Death and Disease is an open-access journal published by Nature Publishing Group. This work is licensed under the Creative Commons Attribution-NonCommercial-No Derivative Works 3.0 Unported License. To view a copy of this license, visit http://creativecommons.org/licenses/by-nc-nd/3.0/

Supplementary Information accompanies the paper on Cell Death and Disease website (http://www.nature.com/cddis) 